\title{
Donor Lymphocyte Infusion
}

National Cancer Institute

\section{Source}

National Cancer Institute. Donor Lymphocyte Infusion. NCI Thesaurus. Code C16145.

The infusion of donor lymphocytes following hematopoietic stem cell transplantation for the purpose of augmenting the host immune response or preventing the rejection of the graft. 